\title{
Author Correction: Giant room temperature anomalous Hall effect and tunable topology in a ferromagnetic topological semimetal $\mathrm{Co}_{2} \mathrm{MnAl}$
}

\author{
Peigang Li, Jahyun Koo, Wei Ning, Jinguo Li, Leixin Miao, Lujin Min, Yanglin Zhu, Yu Wang, Nasim Alem, \\ Chao-Xing Liu (D), Zhiqiang Mao (1) \& Binghai Yan (D)
}

Correction to: Nature Communications https://doi.org/10.1038/s41467-020-17174-9, published online 10 July 2020.

The original version of the Supplementary Information associated with this Article contained an error in Supplementary Figs. 5a and 6 in which the longitudinal resistivity data of the $\mathrm{I} / /(001)$ sample was incorrectly given as the resistance data. In the correct version of Supplementary Figs. 5a and 6, the resistance data has been converted to resistivity by multiplying a geometric factor of 0.667 . The HTML has been updated to include a corrected version of the Supplementary Information.

Published online: 16 September 2020

\footnotetext{
(c) (i) Open Access This article is licensed under a Creative Commons Attribution 4.0 International License, which permits use, sharing, adaptation, distribution and reproduction in any medium or format, as long as you give appropriate credit to the original author(s) and the source, provide a link to the Creative Commons license, and indicate if changes were made. The images or other third party material in this article are included in the article's Creative Commons license, unless indicated otherwise in a credit line to the material. If material is not included in the article's Creative Commons license and your intended use is not permitted by statutory regulation or exceeds the permitted use, you will need to obtain permission directly from the copyright holder. To view a copy of this license, visit http://creativecommons.org/licenses/by/4.0/.
}

() The Author(s) 2020 